\title{
Integration of the Values of "Filial Piety Culture" and the Chinese Laws
}

\author{
Cheng Hua \\ Xinxiang University, Xinxiang, Henan 453003
}

Keywords: Filial piety, values, law, integration

\begin{abstract}
The filial piety culture is a very important part of traditional culture in China. Many ancient laws of China are associated with the filial piety culture, the filial piety culture is also integrated with the current Chinese laws in a lot of aspects, and the filial piety culture reflected in traditional laws can be used to maintain social order. In ancient times, China governed itself by filial piety.
\end{abstract}

\section{Introduction}

The Chinese nation has 5,000 years of excellent traditional culture, and the long history over 5,000 years has created splendid national culture. The traditional "filial piety" culture advocated by China in Chinese culture is one of the cultures attracting greatest attention. The traditional filial piety culture has played a very important role in the long Chinese history, is the core content of the national cohesion of China, and is also a decisive content for the Chinese nation to play a very important role in its history. Human history is constantly advancing, society is also constantly upgrading, and of course, culture is also gradually updated and perfected in constant development. Despite that the new modem civilization is advancing with the times, the essence of traditional culture cannot be abandoned. The traditional culture is the node for understanding the past and reality, and is also the heritage for us modernists to understand history and remember history. Today, we review the traditional "filial piety culture", compare it with the contemporary moral values, and build the socialist new moral culture in the new period and some legal ethics containing the "filial piety culture".

\section{Traditional moral concept of the "filial piety culture" in ancient China}

The "filial piety" referred to in the "filial piety culture" in ancient China refers to an inherited blood relationship and an interpersonal kinship referred to by the inherited blood relationship. In the article titled Word Power Made Easy, the filial piety is explained as that: "filial piety means a person who takes good care of his parents, and is done from the old generation to your generation". The filial piety is inherited by children from the old generation, and is inherited from generation to generation. This tells the people in the world that "filial piety" means to obey and maintain parents, and is also the principle that "taking good care of parents means filial piety" emphasized in ancient times. Confucius has ever said in his book titled Analects of Confucius that "obeying your parents and obeying your brother is the fundamental of benevolence". In this article, the emotions of obeying parents are known as the "filial piety", the emotions of deeply respecting elder brothers are known as fraternal love, and the filial piety and fraternal love are considered as social fundamental laws of social norms and human ethics in ancient society of China. The book titled Classic of Filial Piety proposes that "filial piety is the fundamental of virtue, and all virtues extend from filial piety", which also shows the importance of filial piety in society. Actually, the "filial piety" in a broad sense not only refers to filial piety towards our own parents, but also refers to respect of others' parents. Mencius \& King Hui of Liang (Part I) has mentioned that "do not forget other elderly people who do not have genetic relationship with you when you maintain and care for your own parents, and do not forget other children who do not have genetic relationship with you when you are rearing and educating your own children". The filial piety advocated in ancient times means not only to "respect our own parents and love our own children", but also to respect others' parents, be 
kind to all old people, and love and care for all children. All people in the world are in a pantisocratic society. In the ancient traditional culture of China, filial piety was often extended to monarch system, and many people felt that impiety is disloyal. Originated from Mencius, the wording that "dishonesty to monarch is not filial" shows that filial persons are bound to be loyal persons. The principle of "being filial to your parents at home and being loyal to your country when you are away from home" is the best description of filial piety in a narrow sense and filial piety in a broad sense. The filial piety in ancient China is the fundamental way and norm to maintain good family relationship and maintain good social order. In the traditional feudal system, the filial piety culture in ancient China was the center point of the national ethical thought and culture, and was like the ancient European godfathers and theocracies that ruled the whole country in the middle ages. In the constant revitalization and development of China, the concept of filial piety has always been the fundamental values and cultural traditions of the Chinese people, and has exerted a great influence on the long process of world history.

But everything has dual characters, and such filial culture has a negative side. In the prolonged traditional feudal rule, the filial piety culture also has very strong feudal ideological culture, and the biggest problem of the filial piety culture is slightly blind loyalty. The filial piety culture mainly reflects "three cardinal guides", which request that the liegemen, sons and wives must be absolutely obedient to the monarch, fathers and husbands respectively, and also request that the monarch, fathers and husbands shall set a good example for the liegemen, sons and wives respectively. It reflects a special moral relationship between the monarch and liegemen, between the fathers and sons, and between the husbands and wives in the feudal society.

\section{Modern socialist core value and morality}

Culture is constantly developing, and is unceasingly evolving along with the historical development. Therefore, a lot of culture has very strong characteristics of the times, and the traditional filial piety culture of ancient China is also continuously improved, and achieves advancing with the times with the changes of the history. The contemporary socialist core values also emphasize that some filial piety culture, that is referred to in ancient China, still complies with the current national conditions of China and is still required for modern social development of China, is a kind of penetration and integration of the traditional culture into modern civilization. When the five-starred red flag rises slowly in the Olympic Games, and when the national anthem resounds throughout the Olympic Games, it is believed that every Chinese person will spontaneously have a sense of pride at heart. The athletes make best efforts for national honor, and their behavior is an extension of the ancient filial piety culture and a kind of love for their motherland. When the abbreviated wording "when you, being a citizen of the P.R.C., are in danger overseas, don't give up. No matter how dangerous you are in overseas, please remember that there is a strong motherland behind you." in a passport of China arises in a popular film Wolf Warriors, the patriotic wording enabling people to feel blood-surging will enable us to feel that is not far away from the China dream of realizing the great rejuvenation of the Chinese nation. Such patriotism is reflected in the behavior that ancient Chinese people regard serving their homeland as showing filial piety for their ancestors, is the greatest filial piety and the greatest virtue in the world, and also has the highest value.

\section{Integration of the traditional filial piety culture with modern Chinese laws}

In the modern society, when people blindly pursue interests, there will be the phenomenon that people ignore ethics, thereby requesting us to collect reasonable advantages following contemporary moral ideas from the traditional filial piety culture as one of the bases for formulating and improving Chinese laws. In terms of legislation, "the legal construction in modern society should not only be based on a complete legal system, but also requests the law itself to have reasonable moral values. The true authority of law does not come from the coercive power of China, but from the internal influence of the law and moral legitimacy. Morality is recognized as an 
important standard of good laws. Therefore, the traditional filial piety culture needs to integrate and interact with modern laws, and convert the deep-seated moral ideas acceptable to all the people into laws supported by the coercive power of China, which is the necessary path for people to better abide by and to maintain the social stability and harmony.

Constitution is the fundamental law of China, and has the highest legal effect in China. Relevant provisions in the Constitution provide relevant contents of the filial piety culture. For example, Article 44 in the Constitution provides that "citizens of the People's Republic of China have the right to material assistance from the state and society when they are old. The state develops the social insurance, social relief and medical and health services that are required to enable citizens to enjoy this right." For another example, Article 49 provides that "children who have come of age have the duty to maintain and assist their parents. Maltreatment of old people is prohibited". All these express terms are inheritances of the traditional filial piety culture in China. Of course, relevant provisions on the "filial piety culture" are provided in a lot of laws of China. For example, Paragraph 1 of Article 104 of the General Principles of the Civil Law of the People's Republic of China provides that: "the family, old people and mothers shall be protected by law." Furthermore, the Marriage Law of the People's Republic of China also provides to maintain parents.

As a matter of fact, some provisions in Chinese laws encourage existence of filial behaviors. For example, Article 12 of the Law of Succession of the People's Republic of China provides that: "Widowed daughters-in-law or sons-in-law who have made the predominant contributions in maintaining their parents-in-law shall, in relationship to their parents-in-law, be regarded as successors first in order." Such legal provisions are the provisions guarantee for those who have made maintenance obligations. The traditional excellent culture of respecting the old and cherishing the young is also reflected in the Chinese laws. For example, the Opinions of the Supreme People's Court on Some Issues concerning the Application of the Civil Procedure Law of the People's Republic of China provide that "If several defendants of a case involving claims of alimonies reside in different administrative areas, the case can be under the jurisdiction of the people's court at the domicile of the plaintiff." This lawsuit method greatly facilitates the old people group, and is one aspect reflecting the legal humanization.

Modern laws also have a very strict system for punishing unfilial behaviors, which are generally divided into economic restriction and penal punishment in modern laws. Paragraph 4 in Article 13 of the Law of Succession provides that: "at the time of distributing the estate, successors who had the ability and were in a position to maintain the decedent but failed to fulfil their duties shall be given no share or a smaller share of the estate." Such a Law of Succession is formulated to urge the successors to maintain the elderly. Penal punishment is characterized by deprivation of freedom. As stipulated in Article 260 of the Criminal Law: "Whoever maltreats a member of his family, if the circumstances are flagrant, shall be sentenced to fixed-term imprisonment of not more than two years, criminal detention or public surveillance. Whoever commits the crime mentioned in the preceding paragraph and causes serious injury or death to the victim shall be sentenced to fixed-term imprisonment of not less than two years but not more than seven years”.

\section{Summary}

The filial piety proposed in the "filial piety culture" is an important content for building the socialist core values, and is the primary foundation for family stability and social stability. Society consists of every small family, family harmony is the social harmony, and the family harmony and maintenance is inseparable from the traditional "filial piety culture" of China. The literary quotation that "young sheep know kneeling milk, and young crows feed mother crows back" tells us the importance of taking good care of parents. The filial behaviors as stipulated in Chinese modern law need to be earnestly performed by the general public.

\section{References}

[1] Fei Fei. Filial Piety and Laws in Ancient China [J]. Government Legality, 2017 (5): 38-38. 
[2] Wang Xia. Filial Piety and Traditional Law Concept [J]. Science of Law- Journal of Northwest University of Political \& Law, 1991(5): 30-33.

[3] Wu Tingting and Wu Jiajia. Contradiction and Integration of Traditional Filial Piety Culture and Modern Law [J]. Journal of Wenzhou University (Social Sciences), 2012, 25 (4): 59-64.

[4] Meng Jinghua. On the Ways to Integrate Filial Piety Culture with Modern Laws [J]. Exam Weekly, 2016 (9): 20-20. 